\title{
Modalização na fala espontânea do português brasileiro: um primeiro mapeamento de indices morfolexicais *
}

Modality in Brazilian Portuguese spontaneous speech: a first mapping of morpholexical indexes

\author{
Heliana Mello \\ Universidade Federal de Minas Gerais \\ Janayna Carvalho \\ Universidade Federal de Minas Gerais \\ Priscila Côrtes \\ Universidade Federal de Minas Gerais
}

\begin{abstract}
This paper explores the notion of modality through a corpus of Brazilian Portuguese (BP) spontaneous speech corpus, based on the Speech Patterning Theory (CRESTI, 2000). Morpholexical modality indexes were identified in tone units within each corpus utterance. Through qualitative and quantitative methodologies, it was possible to conclude that: verbs are the major modality agent in BP and the epistemic modality is the most frequent type found. It was also observed that BP allows for multiple modal valency utterances and tone units.
\end{abstract}

Keywords

Modality, Spontaneous speech, Utterance. 


\section{Resumo}

Neste artigo explora-se a noção semântica de modalidade na fala espontânea do português brasileiro (PB) através de um estudo de corpus, cujo objetivo é fazer um levantamento das principais estratégias modalizadoras na fala espontânea do PB. O substrato teórico que orienta esse estudo é a Teoria da Língua em Ato, de Cresti (2000). Buscaram-se os índices modais morfolexicais nas unidades tonais de cada enunciado do corpus, através de procedimentos qualitativos e análise quantitativa, e chegou-se à conclusão de que os verbos são os principais veiculadores de modalização na fala espontânea do PB. O principal tipo de modalidade manifestada é a epistêmica, cobrindo mais de 50\% dos índices encontrados. Observou-se também que é frequente a ocorrência de enunciados e unidades tonais com valências modais múltiplas.

\section{Palavras-chave}

Modalidade, Fala espontânea, Enunciado. 


\section{Introdução}

$\mathrm{O}$

estudo da modalidade vem ocupando a pauta de pesquisa dos estudos lógico-filosóficos e linguísticos há séculos (cf. FINE, 1994). As tradições teóricas desses estudos são variadas e refletem abordagens que vão do formalismo lógico às análises funcionalistas e discursivas da linguagem natural. Em décadas mais recentes, além dos estudos linguísticos clássicos, estudos psicolinguísticos e linguístico-computacionais também passaram a enfocar a modalidade, refletindo, assim, um continuado interesse pela busca da compreensão e descrição dessa categoria (cf. BATLINER et al., 1994). Neste artigo nos interessa o olhar da linguística de uso para o estudo da modalidade, ou seja, buscamos o entendimento dessa categoria através de um estudo empírico. Mais particularmente, interessa-nos o estudo da modalidade não apenas como categoria semântica, mas também o seu uso manifestado contextualmente na fala espontânea. Para desenvolver tal proposta, adotamos como dados de análise as manifestações morfolexicais da modalidade em um subcorpus de fala espontânea do português brasileiro, o C-ORAL-BRASIL. ${ }^{1}$ A base teórica do nosso estudo é a Teoria da Língua em Ato, de Cresti (2000) que propõe ser a fala espontânea composta por enunciados, com uma interface ilocutiva, e divididos em unidades tonais, com correlatos prosódicos. Essa visão teórica, empiricamente embasada, trará consequências para o domínio de aplicação dos índices modais, como será visto na discussão dos nossos dados.

Este artigo é organizado em 4 seções. Inicialmente exploramos o conceito de modalidade e apresentamos o nosso corpus de estudo; passamos, então, a uma discussão metodológica e à análise dos dados para, em seguida, concluirmos e apontarmos perspectivas de continuidade do estudo aqui relatado. 


\section{$1.1 \bigcirc$ que é modalidade?}

A reflexão do filósofo John Venn prenuncia a complexidade da tarefa de se estudar a modalidade. Segundo ele: "[A modalidade] é um tipo de lugar dentre aqueles mais espinhosos e repulsivos no território da lógica” (VENN, 1888, p. 245). ${ }^{2}$ É, de fato, extremamente difícil caracterizar a noção linguística de modalidade. Isso se deve a uma combinação de elementos, dentre os quais: (a) o de tal categoria haver sofrido, em sua tradição de estudo, uma grande influência da Lógica, havendo assim uma mescla entre estudos filosóficos e matemáticos e aqueles da linguagem natural, o que acarreta uma mistura metodológica nem sempre produtiva para o estudo da língua em uso (cf. verificação de valores de verdade); (b) o de essa categoria existir em interrelação, no sistema gramatical de uma língua, com vários fenômenos gramaticais, como tempo, aspecto e modo, prosódia, organização da informação, dentre outros; e (c) o fato de o próprio conceito de modalidade confundir-se com aqueles de atitude, ilocução e emoção.

Apesar disso, é importante salientar que o estudo da modalidade é legítimo e merece demarcação mesmo que a manifestação dessa categoria gramatical nas línguas naturais seja tão fluida. Faz-se necessário, portanto, que se busquem, cada vez com mais rigor, definições coerentes e descrições embasadas no uso linguístico, para uma melhor compreensão da modalidade. Acreditamos, portanto, que estudos com base empírica sejam promissores para tal fim, devido ao aporte observacional que conferem às análises e teorizações delas oriundas.

Ao longo do tempo, o tratamento da modalidade deu-se através das mais diferentes concepções teóricas, acompanhadas de terminologia própria, variando-se, assim, o domínio linguístico levado em conta (sintático, semântico, morfológico ou pragmático) e a relação com outros fenômenos (modo, negação e transitividade, principalmente). É, portanto, improvável que a adoção de uma teoria não privilegie uma manifestação da modalidade em detrimento de outras. Em uma definição muito geral, esquemática de diversas concepções, podemos dizer que

modalidade diz respeito a um domínio semântico que acomoda variadas nuances de sentido, adicionadas a uma hipotética estrutura neutra, qual seja, uma proposição, factual e declarativa. Essa variedade de sentidos encobre um espectro de subclasses que inclui conteúdos semânticos desiderativos, intentivos, hipotéticos, dubidativos, dentre outros (MELLO, 2008, p. 2). 
Assim sendo, independentemente da ênfase que seja dada, os autores que se interessam por esse tema, em geral, concordam que a modalidade, em sua acepção mais fundamental, é composta por várias nuances de sentido, concebidas com base em uma proposição neutra. De forma geral, modalidade é a categoria linguística que indica as intenções, os sentimentos e as atitudes do locutor com relação ao seu discurso. Em outras palavras, é o valor que o emissor atribui aos estados de coisas que descreve ou a que alude em seus enunciados.

\subsection{Distinção e sobreposição de categorias}

Não cabe, no presente trabalho, o escrutínio detalhado sobre o debate acerca das várias acepções de modalidade, dado o objetivo empírico a que se propõe, voltado para dados da fala espontânea. Para tal propósito, remetemos o leitor a Neves (2006), Pessoa (2008) e Mello et al. (2009). Serão apresentados aqui somente os grandes eixos que norteiam a discussão classificatória para a modalidade a fim de estabelecermos um direcionamento taxionômico que subsidie o exame de dados.

Varia, de estudo para estudo, o lócus de aplicação da modalização. Por exemplo, discute-se se seria a proposição a categoria modalizável (cf. BYBEE; FLEISCHMAN, 1995) determinando, portanto, que a modalização é uma entidade semântica - ou seria o enunciado o seu campo de aplicação, assim caracterizando a modalização como uma entidade pragmática (cf. MORAES, 1993). Quanto aos elementos linguísticos passíveis de carregar índices modalizadores, as divergências são ainda maiores. Narrog (2005) faz um levantamento que mostra que, se partirmos de diferentes definições de modalidade, chegaremos a índices diferentes de expressão dessa categoria e poderemos considerar, por exemplo, verbos intransitivos passivizados como modais, além de fenômenos de passivização; causativização; uso desnecessário de honoríficos; uso de sinônimos e usos aspectuais que não correspondem a nuances de um evento. ${ }^{3}$

Em contrapartida, há inúmeros estudos que apresentam posições teóricas divergentes sobre o que é modalidade, mas identificam os mesmos elementos como passíveis de modalização e/ou modalizadores. Quase consensualmente, diversos autores identificam verbos auxiliares e advérbios como marcadores lexicais de modalização. No caso da língua portuguesa, especificamente, são poucos os autores que levam em conta também os adjetivos presentes em 
construções do tipo: "É necessário que você venha"; "É preciso que você me ligue" e, ainda em menor número, os que estudam o adjetivo em si como modalizador ou ainda verbos ou locuções verbais emergentes "é pra fazer”; "dá pra”. Dessa forma, a supremacia da tradição de estudos, principalmente de modais auxiliares, ofusca muitos fenômenos que mereceriam uma atenção cuidadosa em nossa língua. Este estudo (e o projeto em que ele está inserido) é uma das tentativas de preencher a lacuna aqui mencionada.

\subsection{A procedência do subcorpus de análise}

Este estudo foi feito dentro do projeto C-ORAL-BRASIL (cf. RASO; MELLO, 2009) que tem como objetivo maior o estudo do português brasileiro, em sua manifestação como fala espontânea, por meio da compilação de um corpus que segue a arquitetura e critérios observados pelo projeto C-ORALROM (CRESTI; MONEGLIA, 2005), constituindo-se assim como seu quinto braço, somando-se às quatro línguas românicas europeias que o compõem: espanhol, francês, italiano e português europeu. Esse procedimento garante a comparabilidade entre o PB e as quatro línguas componentes do C-ORAL-ROM. Cada um dos subcorpora representa uma variedade diatópica e se divide em duas partes, uma de fala formal e outra, de fala informal, relativas a contextos privados/familiares e públicos. O C-ORAL-BRASIL representa a diatopia mineira, principalmente da região metropolitana de Belo Horizonte, e fornece uma descrição diastrática balanceada.

O corpus tem sua parte informal composta de, aproximadamente, quinze horas de gravações de interações, equivalentes a cento e vinte textos de, em média, 1500 palavras cada um. Procurou-se, na constituição da subparte informal, registrar situações de interações linguísticas acionais variadas, como situações de compra e venda, jogos de mesa, atividade em obra de construção civil, etc, de modo que o material refletisse tanto quanto possível a língua utilizada em situações interacionais espontâneas. O uso acional da linguagem, como nas gravações registradas, permite que os informantes, em vista da atenção voltada à tarefa feita, rapidamente se esqueçam que estão sendo gravados e comuniquem-se com relativa naturalidade. Ademais, o cuidado nas situações escolhidas para gravação se deve à hipótese de que as situações comunicativas refletem a organização informacional da fala e uma grande variedade diafásica espelha as estratégias relevantes da comunicação e, no caso específico deste 
estudo, de uso da modalidade. Todas as gravações foram feitas com gravadores de qualidade considerável para que a organização da estrutura informacional fosse adequadamente identificada no programa WinPitch (cf. RASO; MELLO, 2009). As gravações ocorreram de 2007 a 2010, em Belo Horizonte, MG.

Tanto no projeto C-ORAL-ROM quanto no C-ORAL-BRASIL, o material coletado é transcrito e segmentado de acordo com as diretrizes metodológicas da Teoria da Língua em Ato, proposta por Cresti (2000), que aponta o enunciado como a unidade linguística mínima que pode ser pragmaticamente interpretada, à qual necessariamente se associa uma ilocução. Por ilocução, entende-se uma das três partes do ato de fala austiniano, a qual diz respeito ao tipo de ação realizada através da língua (se asserção, se expressão, se direção, etc.) com o objetivo de atingir, de uma forma determinada, o interlocutor. As outras partes do ato de fala, a perlocução e a locução, também se manifestam em todo enunciado; a perlocução, por se referir à motivação mínima do falante a iniciar um ato de fala; ${ }^{4}$ a locução, pelo fato inerente a todo enunciado de ser dotado de conteúdo locutivo.

A associação do enunciado (domínio linguístico) à ilocução (domínio da ação) é mediada pela prosódia, que permite, então, ao falante reconhecer e produzir diferentes atos de fala. O enunciado é, portanto, a contraparte linguística do ato de fala ligado à ilocução (domínio da ação), cuja contraparte formal éa prosódia. Não há relação necessária entre o enunciado como um todo e a sintaxe sentencial, uma vez que o conceito de enunciado leva em conta aspectos prosódicos e ilocucionários, enão sintáticos. O domínio, por excelência, da sintaxe seria a oração, construto associado à língua escrita. Seguem alguns exemplos de enunciados: ${ }^{5}$

(1) *PAU: <sábado> é o dia d' ele faturar lá no boteco //

*ROG: é //

*ROG: boteco só dá prejuízo //

*PAU: prejuízo e amolação / né // (ipubdl01)

Diversos estudos sobre a manifestação da modalidade no italiano foram feitos por membros do C-ORAL-ROM, como Cresti (2002) e Tucci (2007, 2008, 2009). Ambas assumem que a modalidade é inerente a todo enunciado, com ou sem índices de modalização. No entanto, para tornarem a sua pesquisa viável, elas optaram por fazer um recorte que envolvia os verbos e os advérbios modais 
e adjetivos em posição predicativa. De acordo com Tucci \& Moneglia (no prelo), o domínio de aplicação da modalidade é a unidade tonal; assim sendo, se índices modais estão presentes em unidades distintas de um mesmo enunciado, isso não acarreta composicionalidade. Cresti e Tucci trabalham com três valores modais primordiais (cf. VAN DER AUWERA; PLUNGIAN, 1998), o alético, o deôntico e o epistêmico, com base na definição de modalidade proposta por Bally (1942, apud TUCCI, 2008, p. 2): "Envolvimento do falante com o conteúdo de sua própria locução”, ou seja, o Modus (predicado modal, relativo a uma avaliação subjetiva) do Dictum (predicado verbal, conteúdo denotativo do enunciado). Para a condução da nossa análise, adotaremos os mesmos pressupostos nos quais se pautaram Cresti e Tucci. Por modalidade alética, as autoras entendem a avaliação que o falante faz do estado de coisas segundo noções lógicas de verdade, e a apresentação do estado de coisas como verdadeiro (i.e. em discursos diretos reportados), como ilustram os seguintes exemplos:

\section{(2) "Um cisne pode ser negro" \\ "Um leopardo deve ser malhado"”}

Dessa forma, as noções de capacidade e habilidade também podem se encaixar nessa categoria, uma vez que estão atreladas à verdade no mundo.

A modalidade deôntica está relacionada às noções de permissão e de obrigação, com as quais o falante avalia um estado de coisas referente a alguma ação, como nos exemplos seguintes:

(3) "Não se pode abandonar a pessoa sozinha"»

"Marco deve partir hoje"” (com o sentido semelhante ao de ter que)

Essa categoria, na maneira como as autoras a concebem, não está necessariamente associada ao que é permitido ou vetado convencionalmente, isto é, segundo regras instituídas, mas estende-se também ao posicionamento que o falante faz com relação a uma ação, baseando-se em suas noções de necessidade deôntica. A expressão de desejo, em alguns casos, também se insere nessa categoria, uma vez que o falante posiciona-se perante uma ação.

A modalidade epistêmica manifesta-se sempre que o falante imprime ao estado de coisas uma avaliação baseada em seus conhecimentos e crenças acerca do mundo: 
(4) "Júlio pode ter partido"

"Devem ser os sete"

Nessa categoria, o falante expressa graus de possibilidade e de probabilidade, respectivamente, com relação aos estados de coisas.

\section{Metodologia}

Para este estudo, procedeu-se à análise de 12 textos, de 1500 palavras em média cada, que fazem parte de uma parte seleta do C-ORAL-ROM. Tal subcorpus, a que denominamos minicorpus C-ORAL-BRASIL, é composto de forma a espelhar a composição do corpus completo em sua tipologia textual. O minicorpus, entretanto, é integrado pelas gravações de mais alta qualidade acústica do corpus, além de conter variadas situações acionais. Tal composição satisfez plenamente as nossas necessidades de lidar com dados qualitativamente ricos, porém em uma dimensão quantitativa que permitisse a etiquetagem manual por categoria modal. Ao todo, foram 2573 enunciados completos ${ }^{10}$ analisados. Atribuímos valor modal apenas a enunciados em que há presença de índices modalizadores, que, nos dados analisados, podem ser auxiliares modais (dever, poder), verbos de sentido pleno (achar, pensar, acreditar), advérbios modais (provavelmente, necessariamente, talvez), alguns adjetivos em posição predicativa (é verdade, é preciso), nomes modalizadores (possibilidade, necessidade) e algumas categorias gramaticais manifestas através do verbo (tempo e modo, como o futuro do subjuntivo). ${ }^{11}$ Optamos pelo referido recorte com o objetivo de descrever tendências gerais das estratégias de modalização no português brasileiro. ${ }^{12}$

Consideramos dotados de valor modal epistêmico os verbos, advérbios, adjetivos em posição predicativa e construções que exprimiam, no contexto em questão, o grau de possibilidade e de necessidade ${ }^{13}$ que o falante atribui ao estado de coisas, baseando-se em seus conhecimentos sobre o mundo. Os índices considerados aléticos são aqueles que revelam uma avaliação lógica do estado de coisas, pautada pela realidade. Consideramos modalizadores deônticos todos aqueles que, no contexto, veiculam um valor de obrigatoriedade e de permissão, relacionado ao estado de coisas.

Alguns índices podem funcionar como modalizadores de valores modais múltiplos, como os verbos dever, poder e o advérbio realmente. Nesses casos, 
a análise do contexto é de extrema importância para que se determine o valor modal in situ. O critério que utilizamos para decidir sobre qual o valor modal a ser atribuído a itens plurimodais, como o advérbio realmente, foi o grau de factualidade do estado de coisas, isto é, em (5), por exemplo, esse advérbio veicula um valor alético por estar associado a um estado de coisas que é um fato no mundo:

(5) *HMB: as pessoas falam que [/1] que / é / igual a gente faz mexido aqui // que o resto de comida // mas assim não // a gente vai + na Espanha realmente es fazem isso / né // (ipubmn)

Em outros casos, como em (6), realmente imprime um valor epistêmico ao enunciado, porque fica claro que o falante se baseou em seu julgamento individual para fazer uma avaliação do estado de coisas:

(6) *HMB: de trabalho / de estudo / e de conhecimento mesmo / no // cada vez que cê tenta fazer o prato / cê tenta fazer melhor // né // $<$ tenta > / aperfeiçoar // mas eu acho um / prato / muito legal //

*HRM: <hum hum> // hum hum //

*HMB: muito completo //

*HRM: hum hum //

*HMB: e muito saboroso // muito bonito //

*HRM: é // realmente é // (ipubmn)

\section{Discussão}

Considerando modalizadores os índices morfolexicais já mencionados, encontramos modalizada uma parcela de $9,71 \%$ do corpus de análise, correspondente a 250 enunciados dos 2573 analisados. Dessa parcela modalizada, a maior parte é composta por ocorrências modalizadas epistemicamente (57,85\%). A porcentagem de modalização deôntica é de $23,57 \%$ do total e a de modalização alética é de $18,57 \%$. Os índices modais encontrados figuram na tabela 1 , a seguir. 
TABELA 1

Estratégias lexicais de modalidade, itens correspondentes e porcentagens

\begin{tabular}{l|l|c}
\hline \multicolumn{1}{c|}{$\begin{array}{c}\text { Estratégias lexicais } \\
\text { de modalidade }\end{array}$} & \multicolumn{1}{|c}{ Itens } & $\begin{array}{c}\text { Porcentagem } \\
\text { referente ao total } \\
\text { do corpus }\end{array}$ \\
\hline $\begin{array}{l}\text { Adjetivos (ou nomes com } \\
\text { função adjetiva) em posição } \\
\text { predicativa }\end{array}$ & $\begin{array}{l}\text { (é) lógico, é provável, } \\
\text { importante, (é) verdade }\end{array}$ & $1,42 \%$ \\
\hline $\begin{array}{l}\text { Advérbios ou locuções } \\
\text { adverbiais }\end{array}$ & $\begin{array}{l}\text { Talvez, certamente, realmente, } \\
\text { às vezes, também, logicamente, } \\
\text { sinceramente, com certeza, } \\
\text { completamente, sem dúvida, } \\
\text { possivelmente, na verdade, } \\
\text { na realidade }\end{array}$ & $6,42 \%$ \\
\hline Condicionais & [se X então Y] & $13,21 \%$ \\
\hline Construções modais & $\begin{array}{l}\text { tem condição (de), tem chance } \\
\text { de, o que acontece, ter que, } \\
\text { ficar imaginando, ficar pensando, } \\
\text { (é) para + inf., dá para + inf., } \\
\text { ter certeza, vai saber, tem jeito }\end{array}$ & $22,14 \%$ \\
\hline \begin{tabular}{l} 
Futuro \\
\hline Futuro do pretérito
\end{tabular} & ia ser, ia dar, seria & \\
\hline $\begin{array}{l}\text { Outros } \\
\text { nerbos (no presente, } \\
\text { no infinitivo) }\end{array}$ & $\begin{array}{l}\text { Digamos, de certa forma } \\
\text { acontecer, ver, conseguir, } \\
\text { precisar, pensar, dar e parecer. }\end{array}$ & $3,21 \%$ \\
\hline
\end{tabular}

A discussão sobre a classificação das ocorrências desses índices modalizadores como ocorrências aléticas, epistêmicas ou deônticas é feita nas seções 3.1, 3.2 e 3.3 a seguir.

Além dos índices modais propriamente ditos, como listados acima, há que se notar estratégias textuais de modalização. Discutiremos esse tópico na seção 3.4, na qual exploramos as construções condicionais e os enunciados plurimodalizados, com mais de um índice lexical modalizante. 


\subsection{Modalidade alética}

A expressão desse valor modal se dá através dos seguintes índices: verbo poder; construções como dar para $X$, ter condição e ter chance; e nomes avaliativos, como verdade, em posição predicativa. $\mathrm{O}$ verbo poder, segundo verbo que teve o maior número de ocorrências (35,5\%), expressa possibilidade alética nos dois enunciados seguintes, visto que os falantes atribuem ao estado de coisas um juízo não subjetivo, baseado em indícios do mundo real e que pode ser comprovado como verdadeiro no dado contexto:

(07) *REN: quanto // seis e quarenta-e-oito //

*FLA: <é> // sendo que esse aqui de oito tá //

*REN: quatro e noventa-e-oito //

*FLA: hum hum //

*REN: verdade // a gente pode levar um outro qualquer //

*FLA: é / porque esse Neve é caro // (ifamdl)

(08) *JOR: uma empresa tem a sua despesa administrativa tributária fiscal / é lucro bruto pa poder projetar o lucro líquido // (bpubmn)

A variedade de acepções do verbo dar já é assunto de vários estudos, que enfocam, sobretudo, a sua gramaticalização como auxiliar modal ${ }^{14}$. Nos exemplos seguintes, tem-se a construção dar para $X$, que expressa possibilidade alética:

(09) *MAR: é // No' / se rolar de fazer umas coisas assim / né //

*FAB: então // e / dá pra fazer escuro / sem perder a definição / e manter as peças de fora clara // o' como é que fica legal // (bpubdl)

(10) *CAR: porque até aí / essas criança até dez anos / o [/1] o mundo que nós tamo vivemos hoje / com dez ano já dá pa ver que dá trabalho // (ifammn05)

O verbo dar, embora sem complemento, também apresenta uma acepção gramaticalizada em relação à sua acepção básica no seguinte contexto: 
(11) *CAR: e \&d [/1] cê [/1] \&he / <\&a [/1] aí / acho que / tem> Apis ali / né //

*GET: <agora uma outra abelha também> + tem Apis // é // tem uma Apis forte ali // eu tenho que levar ela embora / porque ali já nu dá mais // quer ver // (ipubdl)

Também nesse caso, ele expressa possibilidade alética.

As construções modais emergem como a segunda mais profícua estratégia de modalização, depois dos verbos, e expressam todos os valores modais. Em seguida, exemplificamos ocorrências de modalização alética pelas construções ter condição e ter chance:

(12) *SHE: hoje eu já tô animada // sabe // vendo / assim / que tem condição // que tem chance // né / de você fazer // (ipubmn)

Outra importante estratégia de modalização são os adjetivos (ou nomes com função adjetiva) em posição predicativa, como no seguinte trecho:

(13) *LUZ: tá levantando poeira // nu tava assim //

*LAU: é verdade / Luzia // a outra vez tava mais tranquila / <né> // (ifamdl)

Nesse trecho, LAU concorda com LUZ após examinar as condições físicas do local por onde passam no momento da enunciação. Consideramos a modalização, nesse caso, alética porque a avaliação é fruto da observação da realidade, sendo, portanto, objetiva.

\subsection{Modalidade epistêmica}

Ocorre expressão de modalidade epistêmica por meio dos seguintes índices: verbos achar, poder e dever; advérbios ou locuções adverbiais, como às vezes, na verdade, com certeza, talvez, logicamente; adjetivos em posição predicativa, como lógico; construção ter certeza; a expressão fixa vai saber; categorias flexionais dos verbos; e outros (digamos, de certa forma).

O verbo achar é o verbo mais frequente, porque aparece em 59 ocorrências de modalidade das 138. Alguns exemplos das ocorrências desse verbo: 
(14) *FLA: outro desse / né // ah / então a gente po' levar / quatro //

*REN: <quatro $>/ /$

*FLA: <não $>/ /$

*REN: desse daqui //

*FLA: estocar // que que <cê acha $>$ //

*REN: <pode> // tanto faz // pode //

*FLA: ou cê acha muito //

*REN: uhn // acho que não // tá // papel < higiênico / eu nunca> + (ifamdl)

(15) *SHE: mas em relação ao tempo eu penso muito nisso assim / de / ter / né // esse tempo de [/1] de [/1] de sentar mesmo e planejar bem mais pra frente // pa nu ficar aquele \&ne [/1] né / aquela coisa assim / \&he / tocada // né // \&he / organizadinha / tudo direitim / plano de aula // \&he / com material adequado / pra aquilo ali //

*LUA: é / eu acho que / uma coisa também que ajudaria nisso / era [/1] era se as [/1] as coordenações nas escolas fossem melhor / né // como é + que que cê acha // porque / o que acontece / nu sei como é que é na sua escola / é que o professor / onde eu dava aula / se vira com tudo // com plano / com \&n [/2] com tudo / né // (ipubmn)

Todas essas ocorrências foram classificadas como epistêmicas, uma vez que nelas o falante ou exprime, por meio do verbo achar, sua impressão sobre algum objeto ou situação em um mundo possível, ou indaga, com uso do mesmo verbo, o ouvinte sobre a sua opinião.

A expressão epistêmica pelo verbo poder geralmente se manifesta em sugestões ou quando o falante pretende suavizar o conteúdo semântico, de um modo eufêmico. O verbo, nesses casos, está preferencialmente na terceira pessoa do pretérito imperfeito, com um sentido de futuro do pretérito.

(16) *MAR: podia fazer até esse detalhe de <pontilhado> aqui por baixo // (bpubdl) 
(17) *ALO: e / ela pediu pa pagar / essa conta // e ocê sabe quanto é que é // eu falei / não / eu / devo ter a conta ainda / porque eu nu + negócio meu eu nu jogo \&f [/1] nada fora / tá tudo guardado // aí / ocê podia olhar pra mim // (ifammn)

(18) *FAB: aí deu o efeito que isso aqui tá por cima disso aqui //

*MAR: é / \&t [/1] tem uns pedaços maior / por exemplo / aqui / a gente podia fazer essa questão // que nem o + mais ou menos na veia / assim / o' // (bpubdl)

Entendemos as sugestões como manifestações epistêmicas porque emergem como expressões subjetivas.

O verbo dever, modal por excelência, tem 9,4 \% de ocorrência, e só veicula modalidade epistêmica, neste corpus. O dever com um senso de obrigação não foi encontrado em nenhuma ocorrência. As suas ocorrências epistêmicas dividem-se entre as de possibilidade e as de probabilidade:

(19) *MAI: o diâmetro dea deve dar uns [/1] uns quarenta a cinquenta centímetro de [/1] de \&s [/2] de grossura / o diâmetro dela // (ifammn)

(20) *LUZ: <oi // boa tarde // a > gente +

\%add: Os informantes dirigem-se ao porteiro da casa de seus amigos.

*POR: <boa tarde> //

*LUZ: eu / e esse carro de trás // nós vamo lá na Maria Elisa e no Duda // ela já deve ter deixado aí // é Luzia / e ele é Tommaso //

De típico modalizador deôntico (por conter a noção de obrigação, associada à dívida), o verbo passou a frequente modalizador epistêmico, veiculando menos a noção de obrigação do que a de possibilidade ou a de probabilidade. A noção de obrigação aparece fracamente na semântica do verbo, porque a avaliação de probabilidade (epistêmico) deriva de uma avaliação baseada na necessidade (deôntica, neste caso) das relações entre as coisas. É notável a ocorrência dessa nova acepção (epistêmica), mais frequente que a acepção de raiz (deôntica).

Vários advérbios e locuções adverbiais com função modalizadora foram encontrados. Alguns são até neologismos, como logicamente, formado por derivação sufixal, com acréscimo do sufixo -mente à base lógica. Seguem 
alguns exemplos de modalização epistêmica, a mais encontrada nos advérbios e locuções adverbiais:

(21) *SHE: então pra ele / é um absurdo ele ter que pagar trinta reais num livro // ele nu tem esse dinheiro em casa // né // como que ele vai investir na [/1] na + pra ele nu é [/2] isso nu é [/2] nu é lucro // né / ele nu vê / sentido no \&di [/2] em ter um + não / trinta reais / aí eu \&j [/2] eu [/1] eu fico imaginando que e’ fica pensando assim / Nossa // às vezes lá em casa tá precisando de fazer uma compra e tudo / né // pra que que eu vou gastar esses trinta reais // com \&l [/2] com livro de inglês //

(22) *HRM: mas se cê fosse fazer um [/1] um jantar / assim / que o prato / de carne na verdade fosse peixe / por exemplo //

(23) *MAI: aí e’ percebeu que [/1] que era essa cobra que e’ já \&vi [/2] já tinha visto \&se [/1] falar nela lá / já tinha visto / talvez ela também //

(24) *BAL: alguém vê que eu sou muito foda $/ /<$ medo $>$ / de perder $\mid<0>$ posto $<$ deles / es vão [/2] es vão $>$ me $\mathrm{xxx} /<$ né $>$ //

*BEL: $<$ eles $>+$ es $<$ iam $>+<$ com certeza $>/ /$

Em (21), uma locução adverbial que tradicionalmente indica frequência (às vezes) funciona como modalizador epistêmico por causa do contexto. A locução na verdade, em (22), assume um valor epistêmico nesse contexto porque se insere numa construção condicional, por meio da qual o falante instaura um mundo possível onde a referida ação aconteceria, o que revela um caráter hipotético e, por isso, epistêmico. As ocorrências (23) e (24) são epistêmicas porque o falante avalia um estado de coisas baseando-se estritamente em suas noções sobre o mundo. Com certeza, em (24), expressa um forte grau de concordância, situado, numa escala de adesão que compreende também os valores intermediários entre o verdadeiro e o falso, acima daquele veiculado pelo talvez de (23).

À semelhança de na verdade, na realidade e realmente, logicamente é um advérbio que poderia, a princípio, ser associado à modalização alética, uma vez que a definição dessa categoria leva em conta uma avaliação do estado de coisas baseada na lógica. Contudo, os contextos em que esses advérbios (e 
locuções) ocorrem acabam por determinar o seu sentido, como no caso seguinte, em que logicamente foi encontrado com um valor epistêmico:

(25) *JOR: e lá eu fiquei um período / desenvolvendo o mesmo tipo de trabalho / logicamente com um salário melhor / hhh e por amizade eu fui cair / em uma multinacional / que eu dei uma virada no produto //

Assim como seu derivado, o adjetivo lógico também é modal:

(26) *SHE: ah / é // \&e [/1] esse aí também é um grande problema / né // o tempo / porque eu / tenho dois cargos // né // não tenho tempo // não tenho tempo de fazer aquele planejamento / igual eu gostaria de fazer / e tal // eu faço é [/1] é uma [/1] um [/1] um rascunho // do que que eu vou fazer naquele dia lá / lógico que nu é em cima da hora / né // mas uns dois [/2] uns dois três dia assim / eu [/1] eu penso / né //

Nesse caso, tem-se o adjetivo lógico empregado com valor epistêmico, porque não há nada de lógico - ou de obrigatório, como a expressão é lógico normalmente sugere - na questão tratada pela informante. A situação é avaliada segundo o que a informante considera obrigatório, o que não torna a modalização alética ou, ainda, deôntica.

A principal construção modal associada à modalização epistêmica é ter certeza, que pode ser intensificada, como acontece a seguir, e transmite a noção de necessidade epistêmica:

(27) *LUZ: eu tive certeza absoluta que eu nu era daqui quando eu saí //

Algumas expressões fixas também podem ser modais. Em alguns contextos, como o representado aqui, a expressão fixa vai saber transmite uma noção de incerteza, e, por se associar ao eixo do conhecimento do falante, foi classificada como epistêmica.

(28) *FAB: <é> // também // de repente um Photoshop //

*MAR: é // vai saber / né //

Estudos mostram que não só vocábulos funcionam como índices modais, mas também algumas categorias flexionais dos verbos, sobretudo tempo e modo 
(cf. BYBEE et al., 1994). Tendo isso em vista, consideramos os verbos conjugados no futuro do pretérito, índices modais sempre epistêmicos, como nas seguintes ocorrências:

(29) *MAR: aquele <que tem ali $>$ //

*FAB: <esse> já seria melhor / aqui no caso // porque pra [/1] pras peças grandes / a <gente já [/1] já pegou > //

(30) *CAR: e / e eu achei que ia me dar trabalho // mas não //

As duas ocorrências são epistêmicas porque o falante ou faz uma conjetura (primeiro caso), ou relata um pensamento hipotético feito no passado (segundo caso). As locuções verbais com o verbo auxiliar no futuro, em alguns contextos, representam estratégia semelhante, como acontece em:

(31) *HMB: se ela gosta de carne / se ela gosta de peixe / se ela gosta de frango / se ela gosta de verdura / e quem nu fala nada / pode ser qualquer coisa / normalmente / nu dá certo // porque / aí / eu vou sugerir de acordo com [/1] com [/1] com o que eu penso //

(32) *SHE: e eu acredito que depois que eu terminar o EDUCONLE / eu acho que aí eu vou tar mais madura ainda / acho que mais preparada //

O contexto é fundamental para que haja modalização nesses casos. Em ambos, o falante posiciona-se epistemicamente com relação a um ponto de referência situacional, marcado pelo aí. Simplesmente uma locução verbal desse tipo, sem essas características contextuais, não seria necessariamente epistêmica. Nos dois exemplos acima, e em outros casos do mesmo tipo, o caráter epistêmico da avaliação prevalece sobre qualquer traço semântico do verbo (i.e. obrigação).

A segunda ocorrência é um exemplo do que Bybee et al. (1994) classificam como expressão de "possibilidade futura”. Para os autores, as ocorrências que indicam alguma previsão se dividem em dois tipos, as que denotam "certeza futura" e as que expressam "possibilidade futura”. No segundo caso, o enunciado émarcado com mais algum índice de possibilidade, além do sintagma verbal com sentido futuro, como, em (32), acontece com o verbo achar.

Por fim, apresentamos as outras estratégias de modalização, que não pertencem a nenhuma categoria anteriormente definida. É o caso de digamos e de certa forma. 
(33) *MAR: <isso aqui / digamos / é uma> segunda camada / também / né //

*FAB: <hum hum > //

(34) *CAR: mas e o pólen / Getúlio // como é que cê tá dando o pólen // *GET: porque pólen / de certa forma ela acha bem por aqui / né / Carlão //

Os dois índices representam uma relativização que o falante faz do estado de coisas que entendemos como epistêmica, porque só pode ser baseada nos conhecimentos de mundo do falante.

\subsection{Modalidade deôntica}

No corpus foram identificadas expressões de modalidade deôntica através do verbo poder e das construções ter que e é para + inf.

As ocorrências deônticas envolvendo o verbo poder, em muitos casos encontrados, estão relacionadas a normas sociais ou a regras específicas a alguns estabelecimentos ou situações. No seguinte trecho, o falante afirma, duas vezes, que não é permitido inscrever-se para dois cargos num mesmo concurso:

(35) *LUZ: nu sei se <pode não > //

*LAU: < não / são> datas diferentes //

*LUZ: ah / são // <são editais diferentes // ah / tá> //

*LAU: <é // é> // não / o [/1] o + são [/1] são + cada departamento tem o seu edital // sua [/1] <seu $>$ [/1] seu modus operandi //

*LUZ: <ham ham> // \&t [/1] tá // tá certo // porque eu acho que no mesmo concurso cê nu pode fazer duas //

O verbo poder, antecedido pela partícula de negação, expressa proibição, modalidade deôntica, portanto; contudo, o valor modal do enunciado, resultante da composição de valores, é epistêmico, uma vez que o falante "acha que não é permitido fazer X”. Nessa situação, em que dois valores diferentes convivem na mesma unidade informacional, que, neste caso, é o enunciado todo, o princípio da composicionalidade não só pode, como deve atuar. As evidências para o julgamento que o falante faz compõem suas noções sobre o mundo, mais especificamente, sobre o modo de funcionamento de concursos públicos. A partir 
de suas crenças, o falante faz uma conjetura que envolve uma outra avaliação, marcada pela noção de proibição.

Entretanto, a maioria dos casos em que o verbo poder está presente ${ }^{15}$ não está associada a valores sociais. O trecho abaixo corrobora isso:

(36) *BEL: <eles > + es <iam> + <com certeza $>/ /<$ é > // pode consertar / ou não //

*BAL: não / \&p [/1] deixa do jeito que <tá> / minha filha //

$*$ BEL: $<$ ahn $>/ /$

*BAL: se cê sentir que ele tá muito deitadinho //

*BEL: ham ham //

*BAL: porque / ele nu pode ficar muito deitado //

Nesse trecho, BEL pergunta se está autorizada a manipular o aparelho de modo a consertá-lo. BAL diz que o aparelho não deve ficar completamente na posição horizontal. Em ambos os casos, um pedido e uma asserção negativamente marcada que exprime proibição, respectivamente, há presença da modalidade deôntica.

Em (37), há a construção ter que, muito frequente, à qual é associado um valor de necessidade deôntica. A construção é pra + inf. (38) transmite a noção de obrigação, por isso é melhor classificada como deôntica.

(37) *HRM: dona Helô / então / me fala / <por exemplo / se eu> fosse / planejar / assim / um [/1] um jantar // me fala uma sugestão //

*HMB: <hhh a cara > // bom // eu nu sugiro jantar / sem a pessoa me falar que que ela gosta de comer $<$ hhh $>$ // porque / cada um / tem um [/1] uma afinidade com um tipo de coisa / gosta / de um tipo de comida / então eu nunca sugiro antes de ter uma [/1] um feedback da pessoa // ela tem que falar / assim / de que que ela gosta //

(38) *CAR: aí entrou todo mundo em parafuso / todo mundo ficou / desesperado / quando [/1] quando ligaram / falaram que era pra / levar de volta // 


\subsection{Estratégias textuais de modalização}

\subsubsection{Construções condicionais}

As construções condicionais apresentam uma organização que desafia a premissa de que o lócus de aplicação da modalidade é a unidade informacional, dessa forma instigando estudos futuros. Tal situação se dá por serem as condicionais uma estratégia textual que ultrapassa o escopo de uma unidade informacional, como verificado nos exemplos extraídos do corpus.

Pesquisas sobre essas estruturas atestam esse fato, como mostrado em Ferrari (2008):

No domínio epistêmico, as condicionais expressam a ideia de que o conhecimento do evento ou do estado de coisas expresso na prótase seria uma condição suficiente para o estabelecimento da conclusão expressa na apódose (FERRARI, 2008).

Assim, tais construções, mais que expressar uma crença ou uma hipótese do interlocutor em relação ao futuro, instauram-na em relação a um evento de modo que o domínio epistêmico possa ser avaliado/ julgado no momento de produção de fala. Um exemplo que corrobora essa análise segue abaixo:

(39) *HMR: dona Helô / então / me fala / <por exemplo / se eu> fosse / planejar / assim / um [/1] um jantar // me fala uma sugestão // (bpubmn01)

O advérbio “assim”, no exemplo acima, é um conector das ideias expressas na prótase e na apódose, mas, além disso, como observa Castilho (1992), reitera o material e é um modalizador. Para Castilho (1992), tal item é um modalizador epistêmico quase asseverativo e, embora não usemos essa nomenclatura, realmente percebe-se que essa palavra, no domínio epistêmico, instaura uma crença ou opinião do ouvinte quase como uma verdade. No contexto acima e em outros examinados, é uma relativização que reforça o julgamento do falante sobre um estado de coisas.

A maioria das condicionais encontradas no trabalho se distribui em duas unidades informacionais e a primeira unidade tem escopo sobre a outra. Isso articula a expressão de probabilidade, característica da modalidade epistêmica, 
com a de certeza absoluta e com a hipótese já expressa pela modalidade epistêmica na primeira unidade informacional:

(40) *CAR: o que tivesse de ser minha / vinha na minha mão // $(\text { bfammn01) })^{16}$

\subsubsection{Mais de um valor modal no enunciado}

Além das estruturas condicionais que apresentam mais de um valor modal no enunciado (no caso de prótase e apódose aparecerem em unidades informacionais diferentes), vários enunciados do corpus trabalhado apresentaram mais de um valor modal. Isso, provavelmente, é motivado, assim como nas condicionais, pela necessidade de articulação das três grandes noções que norteiam o estudo da modalidade: verdade, probabilidade e necessidade. Assim, o falante pode, ao usar itens léxicos que expressam mais de uma noção modal dentro de uma unidade informacional, articulá-las para fins de persuasão ou ênfase de alguma das noções supracitadas. Dos enunciados do corpus, foram encontrados 15 exemplos com mais de um valor modal no enunciado. As especificações estão na Tabela 2, abaixo.

TABELA 2

Enunciados plurimodais

\begin{tabular}{l|c|l}
\hline $\begin{array}{l}\text { Mais de um valor modal } \\
\text { no mesmo enunciado }\end{array}$ & Frequência & Exemplos \\
\hline $\begin{array}{l}\text { Articulação de } 2 \text { índices epistêmicos } \\
\text { na mesma unidade informacional }\end{array}$ & 4 & $\begin{array}{l}\text { *SHE: não / trinta reais / aí eu \&j } \\
{[/ 2] \text { eu [/1] eu fico imaginando que }} \\
\text { e’ fica pensando assim / Nossa // } \\
\text { (bpubmn03) }\end{array}$ \\
\hline $\begin{array}{l}\text { Articulação de } 1 \text { índice deôntico e 1 } \\
\text { índice alético na mesma unidade } \\
\text { informacional }\end{array}$ & 1 & $\begin{array}{l}\text { *MAI: aí / deu a noite / e a mulher nũ } \\
\text { podia sair pa poder / ir atrás de } \\
\text { alguém // (bfammn03) }\end{array}$ \\
\hline $\begin{array}{l}\text { Articulação de } 2 \text { índices epistêmicos } \\
\text { em unidades informacionais } \\
\text { diferentes }\end{array}$ & 3 & $\begin{array}{l}\text { *MAI: ele nũ é muito parente } \\
\text { chegado não / mas \&t [/1] deve ser } \\
\text { / deve ser // (bfammn03) }\end{array}$ \\
\hline
\end{tabular}




\begin{tabular}{l|c|l}
\hline $\begin{array}{l}\text { Articulação de } 3 \text { índices epistêmicos } \\
\text { em unidades informacionais } \\
\text { diferentes }\end{array}$ & 3 & $\begin{array}{l}\text { *SHE: e eu acredito que depois que } \\
\text { eu terminar o EDUCONLE / eu acho } \\
\text { que aí eu vou tar mais madura ainda } \\
\text { / acho que mais preparada // } \\
\text { (bpubmn03) }\end{array}$ \\
\hline $\begin{array}{l}\text { Articulação de } 1 \text { índice epistêmico } \\
\text { e } 1 \text { deôntico em unidades } \\
\text { informacionais diferentes }\end{array}$ & 1 & $\begin{array}{l}\text { *HMB: que eu acho <que azeite> é } \\
\text { um [/2] é um ingrediente / que cê não } \\
\text { pode usar qualquer um // } \\
\text { (bpubmn01) }\end{array}$ \\
\hline $\begin{array}{l}\text { Articulação de } 2 \text { índices deônticos } \\
\text { em unidades informacionais } \\
\text { diferentes }\end{array}$ & 1 & $\begin{array}{l}\text { *HMB: \&he / \&he / cê tem que } \\
\text { pegar os frutos do mar e \&s [/1] tem } \\
\text { que ter um certo conhecimento // } \\
\text { (bpubmn01) }\end{array}$ \\
\hline $\begin{array}{l}\text { Articulação de } 3 \text { índices deônticos } \\
\text { em unidades informacionais } \\
\text { diferentes }\end{array}$ & 1 & $\begin{array}{l}\text { *HMB: cê tem que ir colocando / } \\
\text { ter <aquele> sentimento de // e ver } \\
\text { se tá bom / se tá / no ponto / se nu } \\
\text { tá / <entendeu> // (bpubmn01) }\end{array}$ \\
\hline $\begin{array}{l}\text { Articulação de } 2 \text { índices deônticos } \\
\text { e } 1 \text { alético em unidades } \\
\text { informacionais diferentes }\end{array}$ & 1 & $\begin{array}{l}\text { *CAR: porque / primeiro eu tive que } \\
\text { / contecer uma tragédia comigo / } \\
\text { que tive que perder minha filha / que } \\
\text { é um retratinho que tá ali na estante } \\
\text { /comigo / ela abraçada em mim/pra } \\
\text { / eu / \&he / chegar a essa conclusão } \\
\text { pa mim pegar uma filhinha pa mim } \\
\text { criar // (bfammn01) }\end{array}$ \\
\hline
\end{tabular}

\section{Conclusão}

Neste artigo nos propusemos uma análise preliminar de um subcorpus de fala espontânea do português brasileiro, tendo em vista a identificação e quantificação de índices modalizadores em unidades tonais. Os nossos objetivos eram, sobretudo, verificar as estratégias morfolexicais empregadas na fala espontânea para a veiculação de valoração modal. Partindo de uma análise qualitativa, pautada por um exame manual do subcorpus e, posteriormente, por uma análise balizada quantitativamente, pudemos identificar as seguintes classes e itens morfolexicais modalizadores: 
Verbos (no presente, no pretérito imperfeito e no perfeito do indicativo, no infinitivo): dever, poder, achar, acreditar, acontecer, ver, conseguir, precisar, pensar, dar, parecer

Advérbios ou locuções adverbiais: talvez, certamente, realmente, às vezes, também, logicamente, sinceramente, com certeza, completamente, sem dúvida, possivelmente

Adjetivos em posição predicativa: (é) lógico, é provável, é importante

Construções modais: tem condição (de), tem chance de, o que acontece, ter que, ficar imaginando, ficar pensando, (é) para + inf., dá para + inf., ter certeza, vai saber, tem jeito

Futuro do pretérito: ia ser, ia dar, seria

Futuro: vou + inf.

Condicionais: [se $\mathrm{X}$ então $\mathrm{Y}$ ]

Outros: (é) verdade, digamos, na verdade, de certa forma, na realidade

A partir de uma análise quantitativa, estabelecemos as seguintes porcentagens de ocorrência para cada uma das classes modalizadoras encontradas:

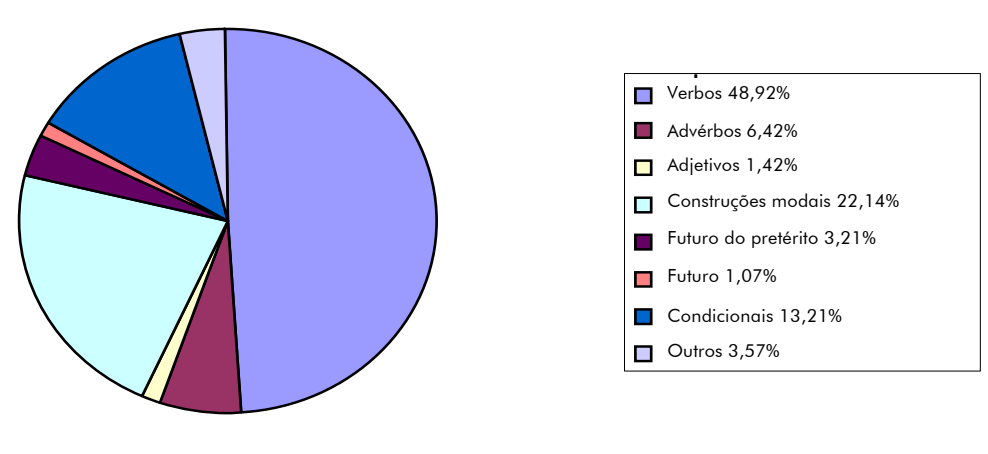

GRÁFICO 1: Porcentagens de ocorrências de classes modalizadoras

Como pode ser observado no Gráfico 1, são os verbos os responsáveis pelo maior índice de codificação modalizadora na fala espontânea, seguidos em 
ordem decrescente por construções modais, construções condicionais, advérbios, outros, futuro do pretérito, adjetivos e futuro simples.

Desdobrando-se a análise dos índices modalizadores de acordo com sua ocorrência em enunciados, nota-se que esses podem ter valência múltipla, ou seja, um mesmo enunciado pode apresentar mais de um índice modal e, nesse caso, esses índices podem ter valores distintos quanto à sua classificação. Sendo o domínio de aplicação da modalidade a unidade tonal, se índices modais estão presentes em unidades distintas de um mesmo enunciado isso não acarreta composicionalidade. Contudo, se ocorrerem no domínio de uma mesma unidade tonal, então a modalidade resultante será constituída a partir de princípios composicionais. Nos dados examinados encontramos as configurações modais em um mesmo enunciado, como explicitadas a seguir: ${ }^{17}$

e-e em unidades diferentes (3), e-e na mesma unidade (4), e-e-e em unidades diferentes (3), e-d na mesma unidade (1), e-d em unidades diferentes (1), d-d em unidades diferentes (1), d-d-d em unidades diferentes (1), d-a na mesma unidade (1), d-d-a em unidades diferentes (1).

Seguindo Tucci (2008), ressaltamos que a articulação da fala, dadas as suas características particulares e distintas da escrita, implica consequências para a expressão da modalidade. É de se notar, sobretudo, que, se na escrita, o domínio de aplicação da modalidade é a proposição, expressa sintaticamente como uma oração, na fala o domínio de aplicação da modalidade é a unidade informacional. Assim, a modalidade enquanto categoria semântica, coerentemente impacta o conteúdo proposicional na escrita e o conteúdo locutivo na fala. Então, se de um lado a sintaxe tem papel crucial para a articulação do texto escrito, a pragmática organiza a fala em enunciados. O nível semântico, ao qual a modalidade está vinculada, está presente tanto na escrita quanto na fala, variando-se apenas o seu lócus de aplicação. Isso não significa dizer que eliminamos a sintaxe como foco analítico na fala-porém, assim como para a modalidade, o domínio de análise da sintaxe restringe-se necessariamente ao interior de uma unidade informacional.

O mapeamento dos índices morfolexicais da modalidade na fala espontânea do PB foram o objetivo principal desse estudo. Deste ponto de partida, contemplam-se inúmeras outras tarefas a serem cumpridas para uma melhor compreensão do papel funcional da modalidade na fala, dentre elas, destacamse: o estudo da modalidade em correlação com as unidades informacionais em que ocorrem, o estudo das unidades informacionais que contêm múltiplas 
valências modais; a exploração refinada de índices modais, as correlações entre tipologias ilocucionárias e padrões de organização de índices modais, o estudo da correlação entre padrões prosódicos e expressão da modalidade, dentre muitos outros estudos a serem vislumbrados.

\section{Notas}

* Este trabalho foi desenvolvido com o apoio do CNPq (Processos 311075/2009-6), FAPEMIG (Processo PPM-00324-08) e Banco Santander. As autoras agradecem as discussões com os colegas do grupo C-ORAL-BRASIL sobre modalidade e sugestões de um parecerista anônimo.

${ }^{1}$ O C-ORAL-BRASIL será descrito na seção 1.3.

${ }^{2}$ Tradução nossa para: “A variety of place upon that most thorny and repulsive of districts in the logical territory".

${ }^{3}$ Vale ressaltar que o autor não afirma que qualquer fenômeno de passivização ou de causativização, por exemplo, poderia ser considerado como expressão de modalidade. Na verdade, ele se detém em mostrar como definições vagas podem nos orientar a rotular muitos fenômenos como expressão de modalidade.

${ }^{4}$ Essa noção de perlocução, diferente da austiniana, é proposta por Cresti no volume I do Corpus di italiano parlato (2000).

${ }^{5}$ A teoria também prevê a segmentação dos enunciados em unidades tonais menores. O final de um enunciado, percebido como de valor terminal, relativo ao cumprimento de uma ilocução, é sinalizado por duas barras (//), e o final de uma unidade tonal é percebido como de valor não terminal e sinalizado por uma barra (/). O símbolo + representa o enunciado interrompido, e o sinal [/n] é referente ao fenômeno de retracting, problema de execução, como cancelamento de palavras que serão imediatamente substituídas por outras que o falante julga mais apropriadas, dentro de um mesmo programa, ou repetição de parte do conteúdo locutivo. O "n” é substituído pelo número de palavras canceladas.

${ }^{6}$ Tradução nossa.

${ }^{7}$ TUCCI, 2007.

${ }^{8}$ TUCCI, 2007.

${ }^{9}$ TUCCI, 2007.

${ }^{10}$ Em oposição aos enunciados interrompidos, que resolvemos descartar por motivos óbvios. 
${ }^{11}$ Para definir quais são os índices modais, baseamo-nos em Neves (2006).

${ }^{12} \mathrm{O}$ estudo do corpus completo possibilitará o levantamento de outras categorias morfológicas associadas à modalização.

${ }^{13}$ Por exemplo, em:

“- Esta moça está lá dentro?

- Deve estar. Quer que mande chamá-la?” (NEVES, 2006.)

${ }^{14}$ Para um aprofundamento nesse tema, veja-se MELLO et al., 2009; SALOMÃO, 2008; SCHER, 2006, entre outros.

${ }^{15}$ Isso se aplica também a outras formas de expressão de modalidade deôntica equivalentes.

${ }^{16}$ Cabe ressaltar que as estruturas são condicionais no que se refere à significação, pois as estruturas sintáticas nem sempre correspondem a "se X, então Y".

${ }^{17}$ Note-se que e representa modalidade epistêmica, $\mathbf{d}$ deôntica e a alética.

\section{Referências}

BATLINER, A.; WEIAND, C.; KIESSLING, A.; NOETH, E. Why sentence modality in spontaneous speech is more difficult to classify and why this fact is not too bad for prosody. ESCA Workshop on Prosody, 1993 - ISCA http://hdl.handle.net/ 10068/152925, 1994.

BYBEE, J.; PERKINS, R.; PAGLIUCA, W. The evolution of grammar. Chicago: The University of Chicago Press, 1994.

BYBEE, J.; FLEISCHMAN, S. Modality and grammar in discourse. Filadélfia e Amsterdã: John Benjamins, 1995.

CASTILHO, A. T.; CASTILHO, C. M. M. Advérbios modalizadores. In: ILARI, Rodolfo (Org.). Gramática do Português Falado - V. II. Campinas: Editora da UNICAMP, 1992. p. 213-260.

CRESTI, E. Corpus di italiano parlato. Firenze: Accademia della Crusca, 2000. 2 v. CRESTI E. Illocuzione e modalità. In: BECCARIA, P.; MARELLO, C. (Ed.). La parola al testo. Scritti per Bice Mortara-Garavelli. Torino: Ed. dell'Orso, 2002. p. 133-145.

CRESTI, E.; MONEGLIA, M. C-ORAL-ROM. Integrated Reference Corpora for Spoken Romance Languages. Amsterdam/Philadelphia: John Benjamins, 2005.

FERRARI, L. V. Reportar condicionais: uma questão de ponto de vista. Revista de Estudos da Linguagem, v. 16, p. 117-140, 2008. 
FINE, K. Essence and modality: the second philosophical perspectives lecture. Philosophical Perspectives, v. 8, Logic and Language, p. 1-16, 1994.

MARTIN, P. WinPitch (www.winpitch.com).

MELLO, Heliana. Índices modais no português brasileiro: um estudo baseado em corpus. Projeto de Pesquisa. PPM- FAPEMIG-00324-08, 2008.

MELLO, H. R.; MELO, E. L.; CARVALHO, J. M.; CORTES, P. O. Prolegômenos sobre modalidade. Domínios de Lingu@gem, v. 5, p. 104-134, 2009.

MORAES, J. A. de. A entoação modal brasileira: fonética e fonologia. In: Cadernos de Estudos Lingüísticos 25, Campinas: UNICAMP, 1993.

NARROG, H. On defining modality again. Language Sciences, v. 27, n. 2, p. 165192, 2005. Disponível em: <www.elsevier.com/locate/pragma>. Acesso em: 18 abr. 2009.

NEVES, M. H. M. Imprimir marcas no enunciado. Ou: A modalização na linguagem. In: NEVES, M. H. M. Texto e gramática. São Paulo: Contexto, 2006. p.151-221.

PESSOA, Nadja. A categoria modalidade e a (in)determinação de fronteiras, 2007. Disponível em: http://www.fflch.usp.br/dlcv/lport/pdf/slp07/09.pdf.

RASO, T.; MELLO, H. Parâmetros de compilação de um corpus oral: o caso do C-ORAL-BRASIL. Revista de Estudos Lingüísticos: Veredas v. 13, n. 2, p. 20-35, 2009.

SALOMÃO, M. M. M. A construção modal com dar no Português do Brasil: metáfora, uso e gramática. Revista de Estudos da Linguagem, v. 16, p. 3, 2008.

SCHER, A. P. Nominalizações em ada, com o verbo leve dar em português brasileiro. Letras de Hoje, Porto Alegre, RS, v. 143, p. 29-48, 2006.

TUCCI, I. L'espressione lessicale della modalità nel parlato spontaneo. Analisi del corpus C-ORAL-ROM Italiano. 2007. 322f. Tese de doutorado (Doutorado em Linguística) - Università degli Studi di Firenze, Firenze, 2007.

TUCCI, I. La modalizzazione nel parlato spontaneo. Relazione tra espressioni lessicali della modalità e unità d'informazione. In: PETTORINO, M.; GIANNINI, A.; VALLONE, M.; SAVY, R. (Ed.). La comunicazione parlata. Atti del Convegno Internazionale (Napoli 23-25 febbraio 2006). Napoli: Liguori, 2008. p. 447-64.

TUCCI, I. La Modalità nel parlato spontaneo e il suo dominio di pertinenza. Una ricerca corpus-based (C-ORAL-ROM Italiano). In: Actes du XXVe Congrès International de linguistique et de philologie romanes (Innsbruck 3-8 septembre 2007). 2009. 
TUCCI, I.; MONEGLIA, M. Modality and illocutionary force in spoken Italian. No prelo.

VAN DER AUWERA, J.; PLUNGIAN, V. Modality's semantic map. Linguistic Typology, v. 2, n. 1, p. 79-124, 1998.

VENN, J. The logic of chance: An Essay on the Foundations and Province of the Theory of Probability. 3. ed. Londres: Macmillan and Company, 1888. Disponível em: <http://www.archive.org/details/logicofchance029416mbp>. Acesso em: 30 jun. 2010. 